\title{
BRCA1 and BRCA2 Mutation Screening Using SmartCycler II High-Resolution Melt Curve Analysis
}

\author{
Scott D. Dufresne, MD; Dorothy R. Belloni, BS; Wendy A. Wells, MD; Gregory J. Tsongalis, PhD
}

- Context.-Real-time polymerase chain reaction technologies have replaced many of the more labor-intense methods in the molecular diagnostics laboratory. Similarly, melt curve analysis can provide a rapid means of mutation screening.

Objective.-To determine if real-time polymerase chain reaction and melt curve analysis using the SmartCycler II could be used as a screening tool for 3 common mutations in BRCA1 and BRCA2.

Design.--Real-time polymerase chain reaction amplification with SYBR Green I detection was performed on DNA from cell lines known to carry the 185delAG or 5382ins C mutation in BRCA1 or the 6174 delT mutation in BRCA2. The melting temperatures and the melt curves were analyzed for differences between wild-type DNA and cell lines that were heterozygous for each mutation.

$B^{\text {ras }}$ RCA1 and BRCA2 function as tumor suppressor genes and encode proteins involved in DNA repair. ${ }^{1}$. Women carrying mutations in these 2 genes have a dramatically increased risk of developing breast and ovarian cancer in their lifetime..$^{2-5}$ More than 400 different mutations have been identified in these 2 genes. However, 3 mutations (185delAG and 5382insC in BRCA1 and 6174delT in $B R C A 2)$ have a combined incidence of greater than $2 \%$ in the Ashkenazi Jewish population. ${ }^{6,7}$ This greatly exceeds the incidence of BRCA mutations found in the general population. Identifying carriers of these mutations is important because interventions such as early breast cancer screening and prophylactic oophorectomy can decrease morbidity and mortality in these patients. ${ }^{8}$

In a clinical setting in which there is an increased risk for a mutation that has not yet been identified in the family, DNA sequencing has become the most common method used for mutation detection. However, mutation screening techniques such as heteroduplex analysis and singlestranded conformational polymorphism analysis have been used as an initial screen before DNA sequencing. Both of these methods are time consuming and labor intensive.

\footnotetext{
Accepted for publication September 13, 2005.

From the Department of Pathology, Dartmouth Medical School, and Dartmouth-Hitchcock Medical Center, Lebanon, $\mathrm{NH}$.

The authors have no relevant financial interest in the products or companies described in this article.

Reprints: Gregory J. Tsongalis, PhD, Department of Pathology, Dartmouth Medical School, Dartmouth-Hitchcock Medical Center, One Medical Center Dr, Lebanon, NH 03756-0001 (e-mail: Gregory.J.Tsongalis@Hitchcock.org).
}

Results.-Significant differences were present in the melt curves for each of the mutations compared with those of the wild-type sequences. The melt curve for the 185delAG mutation showed a separate peak at a lower temperature, which represented the melting temperature of the heteroduplex. For the 6174delT mutation, the melt curve had a shoulder at a lower temperature, while the melt curve for the 5382ins C mutation was shifted to the left and was broader than that for the wild-type sequences.

Conclusions.-High-resolution melt curve analysis is a quick, reliable method for identifying mutations due to small deletions or insertions. As a proof of principle, we used this assay to identify the 3 most common BRCA1 and BRCA2 mutations in the Ashkenazi Jewish population.

(Arch Pathol Lab Med. 2006;130:185-187)

High-resolution melt curve analysis has been used to identify various types of mutations in other genes. ${ }^{9,10}$ The technique detects mutations based on different melting temperatures (Tms) of the complementary double-stranded polymerase chain reaction (PCR) product and the heteroduplexes. An advantage of this technique is that the detection takes place in the same instrument and reaction tube as the amplification. This eliminates postamplification manipulation of the product and makes it much faster and less labor intensive than other screening methods.

In this study, as a proof of principle, we wanted to determine whether melt curve analysis using the SmartCycler II could be used to identify 3 common mutations in the BRCA genes. These genes were selected because they consist of deletions or insertions of only 1 or 2 base pairs (bp).

\section{MATERIALS AND METHODS}

\section{Cell Line Controls}

Genomic DNA samples from cell lines heterozygous for each of the 3 mutations were purchased from Coriell Cell Repositories (Camden, NJ). The BRCA1 185delAG and 5382insC mutant DNAs were from cell lines NA14090 and NA13175, respectively. The BRCA2 6174delT mutant DNA was from cell line NA14170. The mutation status of the DNA from each cell line was confirmed using a PCR-mediated site-directed mutagenesis assay as previously described. ${ }^{11}$

\section{PCR Primers}

The primers used for amplification of the 3 gene segments were purchased from Applied Biosystems (Foster City, Calif) and are described herein. The normal amplicon size (in bp) and calculated Tms for wild-type and mutant sequences are given. 

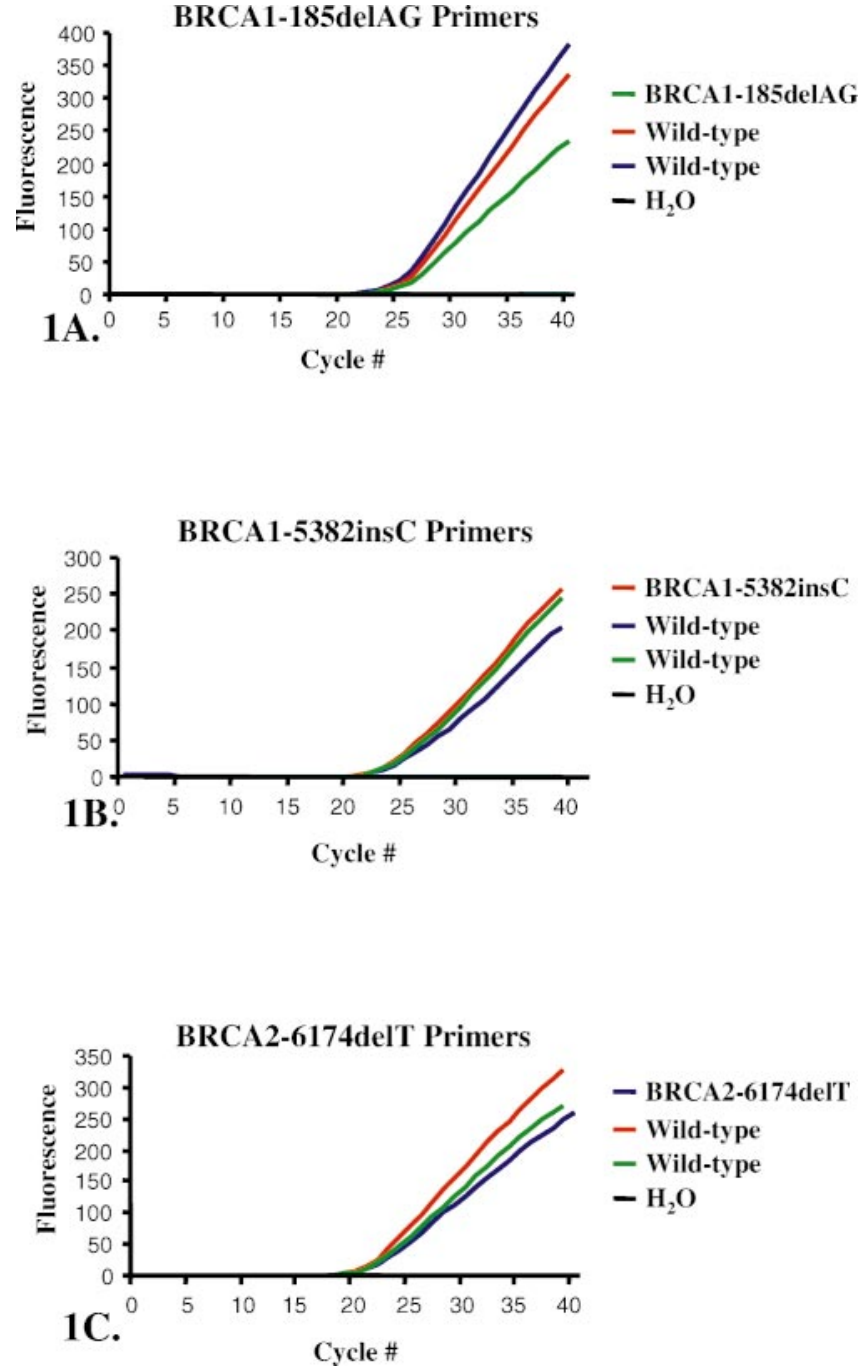

Figure 1. Polymerase chain reaction (PCR) amplification curves. The fluorescence of each PCR reaction is plotted versus the cycle number. $A$, Reactions using the BRCA1 185delAG primers. B, Reactions using the BRCA1 5382insC primers. C, Reactions using the BRCA2 6174delT primers.

BRCA1 185delAG mutation (amplicon size, 70 bp; wild-type Tm, $76^{\circ} \mathrm{C}$; mutant $\left.\mathrm{Tm}, 75^{\circ} \mathrm{C}\right)$ :

Forward primers: 5'-CGTTGAAGAAGTACAAAATGTC-3' Reverse primers: 5'-GCTGACTTACCAGATGGGA-3'

BRCA1 5382insC mutation (amplicon size, 74 bp; wild-type Tm, $81^{\circ} \mathrm{C}$; mutant $\left.\mathrm{Tm}, 81^{\circ} \mathrm{C}\right)$ :

Forward primers: 5'-TCAATGGAAGAAACCACCAA-3'

Reverse primers: 5'-TGAGGGAGGGAGCTTTACCT-3'

BRCA2 6174delT mutation (amplicon size, 69 bp; wild-type Tm, $76^{\circ} \mathrm{C}$; mutant $\left.\mathrm{Tm}, 76^{\circ} \mathrm{C}\right)$ :

Forward primers: 5'-TTGTGGGATTTTTAGCACAGC-3'

Reverse primers: 5'-CTTGCGTTTTGTAATGAAGCA-3'

\section{Real-time PCR}

Each DNA sample was amplified in triplicate with the mutantspecific primers described in the previous subsection by real-time PCR using the SmartCycler II (Cepheid, Sunnyvale, Calif). The DNA samples carrying mutations other than the one for which the primers were designed served as negative controls because the amplified sequences in these samples were normal at that locus.

186 Arch Pathol Lab Med—Vol 130, February 2006

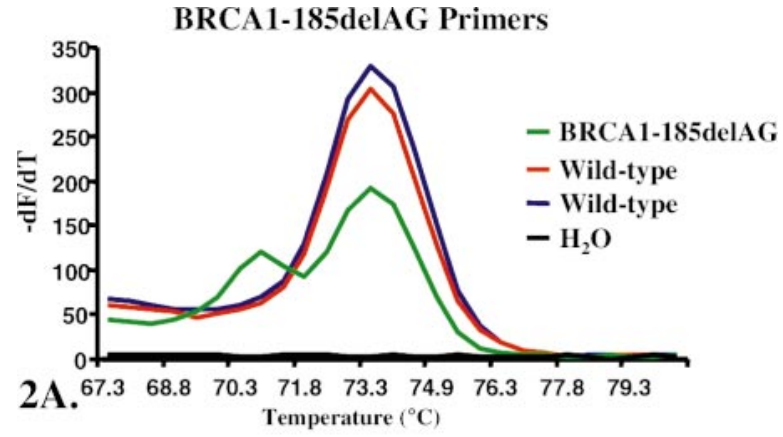

BRCA1-5382insC Primers

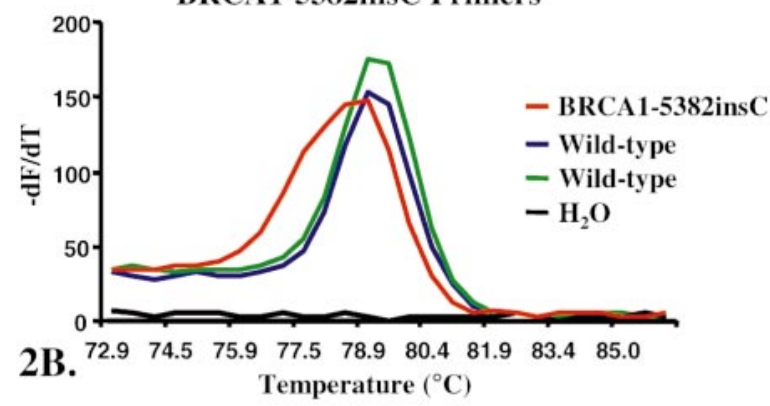

BRCA2-6174delT Primers

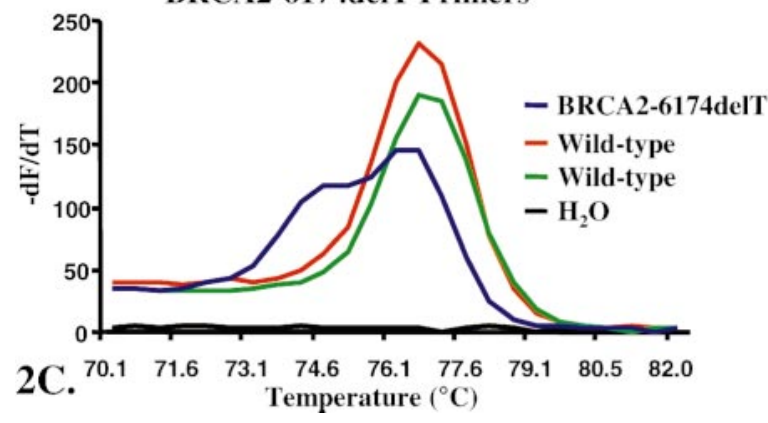

Figure 2. Melt curves. The negative of the first derivative of each melt curve is plotted versus the temperature. Genomic DNA carrying mutations other than the one amplified serve as negative controls because the amplified sequence in these samples is normal. A, Reactions using the BRCA1 185delAG primers. B, Reactions using the BRCA1 5382 insC primers. $C$, Reactions using the BRCA2 6174delT primers.

Polymerase chain reaction was carried out in a total volume of $25 \mu \mathrm{L}$ containing $2 \mu \mathrm{L}$ of genomic DNA (70 ng), $1 \mu \mathrm{L}$ of primer mix (containing $25 \mathrm{pmol}$ of the forward and reverse primers in water), $12.5 \mu \mathrm{L}$ of SYBR Green I master mix (Applied Biosystems), and $9.5 \mu \mathrm{L}$ of water. The PCR conditions were as follows: an activation step at $95^{\circ} \mathrm{C}$ for 10 minutes followed by 40 cycles of denaturation at $95^{\circ} \mathrm{C}$ for 15 seconds, annealing at $60^{\circ} \mathrm{C}$ for 30 seconds, and extension at $72^{\circ} \mathrm{C}$ for 30 seconds.

\section{Melt Curve Analysis}

Depending on the Tm of a specific amplicon, the melt curve identifies a characteristic Tm that can distinguish between amplicons that differ by only a single base. For our study, melt curve analysis was performed in triplicate following PCR amplification. The PCR amplicons were heated to $95^{\circ} \mathrm{C}$ for 5 minutes and then cooled to $40^{\circ} \mathrm{C}$ for 5 minutes. Using the SYBR Green I channel, melt curve data were then collected from $40^{\circ} \mathrm{C}$ to $95^{\circ} \mathrm{C}$ at a ramping rate of $0.5^{\circ} \mathrm{C}$ per second with the optics on. 


\section{RESULTS}

The PCR amplification curves for each reaction are shown in Figure 1. The cycle threshold values were as follows: 27.0 for BRCA1 185delAG (Figure 1, A), 26.6 for BRCA1 5382insC (Figure 1, B), and 23.1 for BRCA2 6174delT (Figure 1, C).

Melt curve analysis was then performed on all replicate PCR samples. The specific Tms for wild-type and mutant sequences were determined in triplicate. Replicate Tms for wild-type and mutant sequences were within $1^{\circ} \mathrm{C}$ of each other for the different mutations, and the shapes of the curves were indicative of heteroduplex formations between mutant and wild-type alleles.

The melt curves of the amplified BRCA1 185delAG products (Figure 2, A) showed a single peak at $73.5^{\circ} \mathrm{C}$ with the control wild-type DNA. The heterozygous control DNA sample for this mutation, however, showed an additional peak at $71^{\circ} \mathrm{C}$. This lower peak represents the Tm of the heteroduplex that consists of 1 wild-type strand and 1 mutant strand.

The melt curve of the BRCA1 5382insC amplified product (Figure 2, B) had a Tm of $79.2^{\circ} \mathrm{C}$ in the wild-type sequence. The DNA from the heterozygous sample for this mutation showed a broadened melt curve and a shift of the curve to the left. Although a distinct separate peak is not seen in this case, the shape of this peak is consistent with a Tm of the heteroduplex being very close to that of the complementary normal or wild-type sequence.

The melt curve of the BRCA2 6174delT amplified product (Figure 2, C) showed a shoulder to the left of the main peak, representing melting of the heteroduplex in the DNA heterozygous for this mutation. This shoulder is absent in the DNA samples containing wild-type sequence.

\section{COMMENT}

In this study, we show that high-resolution melt curve analysis can be used successfully to identify the 3 most common BRCA1 and BRCA2 mutations in the Ashkenazi Jewish population. This technique can detect a 1-bp difference in PCR-amplified products and eliminates the need for DNA sequencing or electrophoresis to detect these mutations. Because the reaction and analysis take place in the same instrument, the only manual component to the test is setting up the reactions. Our total turnaround time for this procedure was less than 2 hours.
Using cell line control DNA, the described set of primers appears to be specific for the given mutations. However, it is possible that in some patient samples some other mutations or polymorphisms may be found within these amplified products. In that case, the melt curves for these genetic alterations would result in Tms that are different from those of the wild-type or the mutation sequences being screened for. These cases would require sequencing to identify the specific mutation, unless known mutant control DNA was also analyzed for each.

High-resolution melt curve analysis is a useful method to screen for the 3 most common BRCA1 and BRCA2 mutations in the Ashkenazi Jewish population. In addition, this technique may be efficient in screening for other mutations in oncogenes and tumor suppressor genes. Furthermore, we have demonstrated that high-resolution melt curve analysis can identify small deletions or insertions, as characterized by the 3 mutations analyzed in this study.

\section{References}

1. Chen $\mathrm{Y}$, Lee $\mathrm{WH}$, Chew HK. Emerging roles of BRCA1 in transcriptional regulation and DNA repair. J Cell Physiol. 1999;181:385-392.

2. Struewing JP, Hartge $P$, Wacholder $S$, et al. The risk of cancer associated with specific mutations of BRCA1 and BRCA2 among Ashkenazi Jews. N Engl J Med. 1997;336:1401-1408.

3. Ford D, Easton DF, Stratton M, et al, Breast Cancer Linkage Consortium. Genetic heterogeneity and penetrance analysis of the BRCA1 and BRCA2 genes in breast cancer families. Am J Hum Genet. 1998;62:676-689.

4. King MC, Marks JH, Mandell JB, New York Breast Cancer Study Group. Breast and ovarian cancer risks due to inherited mutations in BRCA1 and BRCA2. Science. 2003;302:643-646.

5. Satagopan JM, Boyd J, Kauff ND, et al. Ovarian cancer risk in Ashkenazi Jewish carriers of BRCA1 and BRCA2 mutations. Clin Cancer Res. 2002;8:37763781 .

6. Roa BB, Boyd AA, Volcik K, Richards CS. Ashkenazi Jewish population frequencies for common mutations in BRCA1 and BRCA2. Nat Genet. 1996;14:185187.

7. Struewing JP, Abeliovich D, Peretz T, et al. The carrier frequency of the BRCA1 185delAG mutation is approximately 1 percent in Ashkenazi Jewish individuals [published correction appears in Nat Genet. 1996;12:110]. Nat Genet. 1995; 11:198-200.

8. Kauff ND, Satagopan JM, Robson ME, et al. Risk-reducing salpingo-oophorectomy in women with a BRCA1 or BRCA2 mutation. N Engl J Med. 2002;346: 1609-1615.

9. Wittwer CT, Reed GH, Gundry CN, Vandersteen JG, Pryor RJ. High-resolution genotyping by amplicon melting analysis using LCGreen. Clin Chem. 2003; 49(pt 1):853-860.

10. Zhou L, Myers AN, Vandersteen JG, Wang L, Wittwer CT. Closed-tube genotyping with unlabeled oligonucleotide probes and a saturating DNA dye. Clin Chem. 2004;50:1328-1335.

11. Tsongalis GJ, Linfert DR, Johnson RC, Ackroyd R, Berman MM, Ricci A Jr. Double heterozygosity for mutations in the BRCA1 and BRCA2 genes in a breast cancer patient. Arch Pathol Lab Med. 1998;122:548-550. 